\title{
Discussion on the Funeral Music in Bashu
}

\author{
Xiaoan Zeng, Xiaomei Zeng \\ China West Normal University, Nanchong, 637002, China
}

\begin{abstract}
Keywords: Sichuan, Northeastern Sichuan, Han nationality, Funeral ceremony, Music culture, Characteristic
\end{abstract}

\begin{abstract}
The land of Bashu, which is the land of abundance - Sichuan. It is a place full of outstanding people and nature's treasures, and in this precious place, it contains various local folk music cultures with profound connotations and multiple forms, and the funeral ceremony of Han nationality in Northeastern Sichuan is one of them. As a kind of local social culture, it has formed a set of abundant and mature system with strong national characteristic. In this paper, it intends to explore the unique construction and feature of ceremony culture in the funeral ceremony of Han nationality in Northeastern Sichuan, and attempts to experience all kinds of values contained in such long inherited folk art form.
\end{abstract}

\section{Introduction}

Bashu area is located in the edge of Sichuan Basin, and due to its complexity of its topography leads to the inconvenience of traffic, so for many years, the Northeastern Sichuan region is always in the state of economic deficiency and backward cultural life. But just such kind of state makes some local traditional and cultural art forms can be saved in good condition. For local people, such ancient art form does not fade with the development of time, but keeps its original color and taste from beginning to end, which is believed and worshiped by people.

\section{Summary of Funeral Ceremony and Music Culture of Han Nationality in Bashu Area}

In the funeral ceremony of Han nationality in Bashu area, it spreads two kinds of ancient traditional ideas and concepts: "ancestor worship" and "endless soul”, and both of them are deeply influenced the local people, which forms their funeral concept of "taking death calmly". Therefore, when burying death people, Han people in Northeastern Sichuan not only emphasize on their body and soul, but also form a set of funeral ceremony with strong local characteristics in the long inherited humanistic and moral concerns. In this set of funeral ceremony, it emits a smell of ethics and morality from beginning to end, which has established the extremely profound behavior standards and norms for this society.

In the funeral ceremony of Bashu area, the ceremony music in the most important part in the whole process, and it connects each part in the ceremony, which is mainly cry and chant, gathering the musical art parts such as singing, dancing and instrument. Through the ceremony music, people express their inner emotions and display various folk customs on the ceremony, so at first, the expression forms for such kind of funeral music are diverse. To be specified, they use the difference between the lyrics and the content of songs to show different music expression types, such as "scattered crying" and "covering head", and people use the above two music forms to express their yearnings toward the dead people. In addition, the musical natures of tunes in the ceremony music are changeable, such as the crying singing and talking singing songs in the funeral and the funeral oration, the Took of Songs and confession chanted in the dojo and Buddhist ceremony. In terms of vocal music tone, it follows the Chinese traditional five tones "Gong, Shang, Jue, Zhi and Yu". Just as the Crying Mourning Tone in Sima Town in Pingchang County, it is mainly "Gong and Yu" tones. In total, the funeral music in Bashu more focuses on advocating humanistic and moral ideas such as Confucian ethics and rites, so the style and melody of music are smooth and soothing, which are typical religious music. 


\section{Music on the Funeral Ceremony of Han Nationality in Bashu Area}

\section{Music Tone and Category}

The funeral ceremony of Han nationality in Bashu area focuses on the expression forms of music and the coordination of people's singing and the instruments, so the local people call the music expression form in the funeral ceremony as "funeral ceremony". If divides its music category according to the song structure and the content of lyrics, it can be divided into "scattered crying" and "covering head".

\section{Scattered crying}

"Scattered crying" is characterized by freedom, which cries with the mood without any restrictions, and is mainly to express the condolences and yearnings for dead people, such as eulogizing the hardworking of the dead people before their death or blaming they do not do their emotional obligations and responsibilities. Cry the Husband Die Early in Liangshan Fushan County is a ten-sentence filial song featured by such "scattered crying" expression. The whole song only has two sentences, but it has a very strong taste of dialect speech, which mainly tells the daughter laments her unbearable suffering life to her father. While in Crying Husband, it expresses the sadness and desperation of women who lose her hushand in front of the grave. In "Daughter-in-law Crying the Father-in-law" in Santai County and "My Mother is Busy for Children Day and Night" in Jiulongpo Town, they express the condolences of crying people towards the dead relatives from different angles, so the music expression form "scattered crying" is the most folk and lively music form on the funeral ceremony, almost every person in Bashu area can use the "scattered crying" way to express the yearnings to the dead relatives.

\section{Covering head}

"Covering head" is relatively cultured, which applies some stylized content and sentence to reflect the emotions on the funeral ceremony. In general, "covering head" is good at telling the story in chronological order. For example, Crying for the Whole Night and Crying for the Mother describe the whole process of the mother from illness till die and burying in Qing Mountain, which contains the yearnings of people alive toward dead people. These songs is not only for expressing condolences on the funeral ceremony, the more important thing is hoping to use this particular expression form of folk music to advise that people should practice filial piety to elderly people when thy are still alive, love their elders, love work and love life.

Whether it is "scattered crying" or "covering head", they should be carried out according to the combination of traditional rites and the specific aspects of funeral ceremony, so from the generalized perspective, they are different from the music form in the ordinary funeral ceremony. In the generalized funeral ceremony, singing songs mostly are the ritual songs related to religion and folk sacrifice. Their art forms have a wide range and abundant contents. In other words, these songs may also appear on other rituals. While the funeral songs of Han nationality in Eastern Sichuan are limited to appear in the specific part of the local funeral ceremony, and are absolutely impossible to appear in other parts of the other ceremonies. So this kind of music form has a reference and pertinence. For example, Cutting the Coffin in Santai County is the songs only applied to the preparation of the coffin, while Open the Road can only be singed when opening the road on the funeral ceremony. There are similar songs, such as Welcome God when welcoming the gods to come in the salvation rituals, and Welcome Guests when welcoming the relatives and friends to come to express their condolences, etc.

\section{Structure and Relationship between Lyrics and Songs in the Music}

The content of funeral music of Han nationality in Bashu area is mainly expressed through the lyrics, so the syntax and structural features of the lyrics become the important influence elements to express people's thoughts and feelings, which jointly restrict the song and syntactic structure in the whole 
music. Modern music researchers divide them into "Miscellaneous word type" and "Homogeneous word type".

\section{Lyrics Structure}

\section{Homogeneous word type}

For the homogeneous word type, the sentence structure of lyrics is relatively neat, and each sentence is composed by the words with same number. The funeral songs in Bashu area are commonly four-word sentence, five-word sentence and seven-word sentence, in which seven-word sentence is the most common one. Others are four-word sentence such are Words for Coffin Closing in Northern Sichuan, which generally can not find a regular rhyme, but also can find the situation has the same rhyme for many sentences; while five-word sentence mostly have the same rhyme on the first, second and fourth sentence, such as Filial Song in Yilong County, and Song for Placing the Coffin in Fengjie County, which not only have more rhymes and have the same rhyme for the whole song. Songs in the homogeneous word type have such features, which have neat sentence, many rhymes, and abundant rules and are easy to grasp.

Miscellaneous word type

"Long and short sentence type" is the miscellaneous word type, and just as its name implies, it is the sentence structure composed by long and short sentences. Compared with the homogeneous word type, the miscellaneous word type has no constitution rules from the structure of arranging words, but it is stronger and more direct in expressing the content on the funeral ceremony and the emotion of mourners. In the songs of miscellaneous word type, they also have the same expression form of one rhyme in the whole song, such as the Funeral Haozi in Fengjing County. But taken as a whole, the lyrics in the miscellaneous word type are not in accordance with the rules to rhyme. But in order to sing with a strong sense of rhythm, it is common to see the phenomenon of same rhyme in every end of the sentence in the lyrics.

Whether the miscellaneous word type or the homogeneous word type, from the syntactic features of lyrics in funeral music of Han nationality in Bashu area, we can see that the way to use rhyme is entirely from ancient poetries and the Book of Songs. While the five-word sentence and seven-word sentence completely emulate the ancient poetries, such the development of folk music is restricted by the development and restraints of many things, and this truth is reflected more vividly in the process of evolution and change in the funeral songs of Han nationality in Bashu area.

\section{Instruments and Musical Notations in the Funeral Ceremony of Han Nationality in Bashu Area}

\section{Instruments}

The funeral ceremony of Han nationality in Bashu area not only pays attention to singing, but also focuses on instrumental music, which is also an important part of the funeral ceremony in traditional folk, and due to the existence of instrumental music, the ceremony can have the atmosphere. In the Han area in Bashu area, two most important expression forms are "gong and drum ensemble" and "wind instrument and percussion". They appear and are played at the funeral ceremony, in which gong and drum ensemble is the principal thing and wind instrument and percussion is the supplement.

In order to show the two musical forms, it must use a variety of instruments, such as gongs, cymbals, drums, bag gongs, suona, wooden fish and conch, etc. Funeral music requires these instruments to have a clear division, be steady and orderly in the ceremony, such as grasping the rhythm of the horse gong in the process, bag gongs usually used in the dojo practices, wooden fish when chanting and confessing, or the ox horns and conches in the Buddhist ceremonies.

\section{Musical Notations}

The funeral music of Han nationality in Bashu area mainly adopts the notation recording way with shape and sound words. At this point, the ways for recording the notation in various areas in Northeastern Sichuan have their own characteristics. For example, Sima Town in Pingchang County adopts the notation recording way with shape and sound words, which are mainly the recording ways of gong and drum notation. This folk way of recoding the notation has been inherited for hundreds of years, which is very old, and appears and spread in the folk at that time. In this way of recording the 
notation, $\circ$ represents gong, $\mathrm{x}$ represents cymbals, o represents beating drum or beating the edge of gong, and $\Delta$ represents beating the gong.

\section{Musical Structure in the Funeral Ceremony in Bashu Area}

For the musical tones of gongs and drums on the funeral ceremony, there are three kinds for general development, which are repetition, variation and contrast.

First is repetition, which is the reproduction of the nature of music. It is divided into single shot, small chapter and musical phrase in every appearance. For example, the last sentence in Phoenix Nodding is a typical liberal repetition. The main purpose of its single-beat rhythm is to expand the musical phrase. In the tune name Three Cycle, the liberal repetition in the end sentence enables the reproduction of the whole small chapter.

Variation emphasizes on the basis, which uses the original musical materials as the basis, and then uses the way of adding flowers and changing rhythms to show the different sounds of different musical instruments, and finally makes the music to show different degrees of change. For example, in the tune name Liangzi, there are basic rhythms, adding flowers and variations. In this tune name, it adds the musical instrument cymbals, and the playing method adopts beating both gongs and cymbals, so that the music can be perfectly completed in the climax and make people feel boundless.

The last is contrast. It gives full use of different materials in the front and back part in a song to conduct music contrast, which also can be called echoes. The tune name Double Phoenix has such contrast, and its first two sentences belong to the connection with strict and repeated constitution, while the third sentence introduces new musical materials, such as cymbals, so that it makes the establishment of contrast relationship. As a result, the alternation of different instruments makes the whole song have a colorful vitality, producing a unique beauty in the hearing to the audience.

\section{Cultural Manifestation of Musical Text in the Funeral Ceremony in Bashu Area}

\section{Miss}

Miss is the feeling of miss towards relatives. Such topics can lead to social resonation also has many expression forms in the funeral ceremony of Han nationality in Bashu area. Daily etiquettes such as lighting candles, libation, incensing and sweeping also have demonstrated for the feeling of miss towards relatives. Of course, using the music to express the filial love is also a local geographical feature. In the Han nationality in Bashu area, there are many songs express the filial loves in the funeral ceremony, such as Song for Crying the Soul in Fengjing County:

Can't see father takes the dishes, and can't see mother sieves the wine;

Parent passes the boundary of death and living, holding coffins with tears and sorrow;

One lonely lamp illuminates the morning hall, crying the dead father and mother;

Painstaking and hardworking become fantasy, and only see few lines in spirit tablet;

The love of parenting is wide, which can not be forgotten by children all the time;

Think when walking and sitting, and crying father and mother at day and night.

In this song, the creator carefully describe the details of family life before and after the death of father and mother, even including the emotional changes of people around, and just a few sentences show the grief of losing parent and the children's deepest love of miss towards them.

\section{Sadness}

Sadness is the struggle of people of Han nationally in Northeastern Sichuan towards the traditional bad habits, so there are many local funeral music topics expressing the sad feelings, demonstrating the human interest of locals. Such subjects always have a strong plot of sadness, reflecting the helplessness of people toward the society and the life, such as Crying for Father:

Someone asks on the road to bury, talking about the parent has a good reputation;

Vegetable seeds in the fertile land are three inches higher, and vegetable seeds in the infertile land are three inches shorter;

Others take their daughter as treasures, but you do not take the daughter as a person; 
Tonight my father sleeps with high pillows, and slowly thinks from the heart.

The song Crying for Father profoundly reveals the ancient feudal thoughts and concepts in our ancient Northeastern Sichuan area. It can be said that in the time of popular thought of "preferring boys to girls", such kind of songs are various and are not surprising. Many families abandon their daughters forced by their living pressure. When the daughters grow up and go back to the graves of their dissatisfactions towards parents and the society, reflecting the frustration and impermanence. Nowadays, with the development of time, the democratic consciousness of families in our vast areas of Northeastern Sichuan has been improved, and the feudal thought of preferring boys to girls has also changed, but such kind of songs still exist, which plays an educational and warning effect, so that it makes some people with traditional ideas can be awakened soon.

\section{Conclusion}

After a brief understanding of the music and its culture in the funeral ceremony of Han nationality in Northeastern Sichuan, we find that the local natural environment and traditions nourish the cultural and artistic form such as the funeral music. It is the root of music, and is the motive power for developing the development of music, which are what society needs. Of course, as a kind of culture, folk music constantly educates the generations of people to understand the truth of survival and development. Only in this way, the folk music itself has the condition and significance to be continuously inherited.

\section{Acknowledgments}

This paper is the research achievement of the key topic Arrangement and Research on the Folk Music Culture in Northeastern Sichuan (Project Number: 14SA0069) in the humanities and social sciences in Sichuan Provincial Department of Education

\section{References}

[1] Luo Liangxing. Study on the Funeral Ceremony and its Musical Culture of Han Nationality in Northeastern Sichuan. Sichuan Normal University, 2009.

[2] Zhu Jiangshu. Exhaustive Studying with the Heart Tied on the Musical Instruments - My Father Zhu Zemin and the Ancient Guqin Music in Bashu. Explorations in Music, 2013 (1).

[3] Li Hongchun. A General Survey of Current Studies on Funeral Music. Cultural and Artistic Research, 2011 (4). 